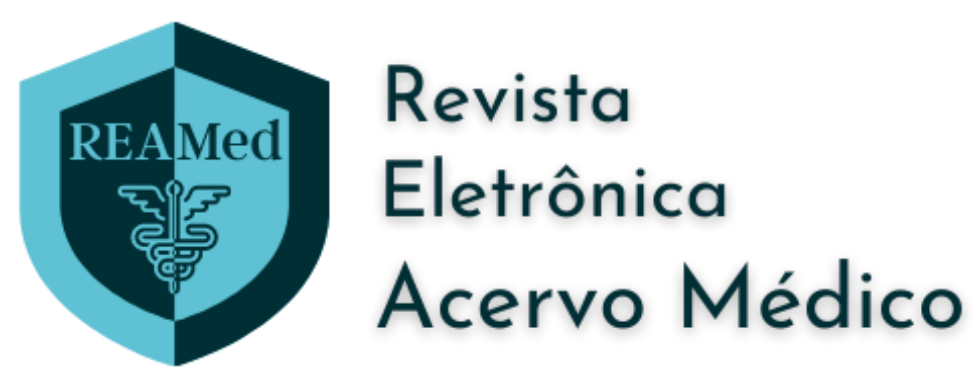

\title{
Manifestações oculares de doenças reumatológicas
}

\author{
Ocular manifestations of rheumatologic diseases \\ Manifestaciones oculares de enfermedades reumatológicas
}

Luiz Valério Costa Vasconcelos ${ }^{1 *}$, Beatriz Patriota Saraiva Costa ${ }^{2}$, Christian Armando Barreto Fortón ${ }^{3}$, Julia de Oliveira Bernardino ${ }^{4}$, Juliane Lima Fonseca Brayner ${ }^{1}$, Maria Gabriella Borges Braga $^{4}$, Michelly Guizini ${ }^{6}$, Nicole Gonzaga Gonçalves ${ }^{2}$, Rafael Barroso de Vasconcelos ${ }^{1}$, Ariany de Assis Moura'.

\section{RESUMO}

Objetivo: Analisar sobre as diversas alterações oculares relacionadas às doenças reumáticas, assim como discorrer sobre sua etiologia, fisiopatologia, manifestações clínicas, fatores de risco, abordagem diagnóstica e terapêutica. Revisão bibliográfica: As doenças reumáticas, designadas autoimunes, ocorrem quando o sistema imunológico reage contra células saudáveis, causando inflamações que acometem, principalmente, o sistema locomotor. O diagnóstico baseia-se na história e no exame físico, já que exames laboratoriais apresentam baixa sensibilidade e especificidade. Portanto, a identificação é árdua e muitas vezes pode ser confundida com outras patologias. Ademais, os pacientes que apresentam as doenças autoimunes podem desenvolver moléstias secundárias, e como exemplo, complicações oculares, entre elas a uveíte, ceratoconjuntivite seca, episclerite, esclerite, entre outras. Desse modo, as manifestações variam de acordo com o tipo de reumatismo expresso, assim como o tratamento a ser aplicado. Considerações finais: Os distúrbios reumáticos provocam manifestações oculares que devem ser acompanhadas por profissionais da área, a fim de prevenir e/ou diagnosticá-las.

Palavras-chave: Doenças reumáticas, Manifestações oculares, Oftalmopatias.

\begin{abstract}
Objective: Analyze about the various ocular alterations related to rheumatic diseases, as well as to discuss their etiology, pathophysiology, clinical manifestations, risk factors, diagnostic and therapeutic approach. Bibliographic review: Rheumatic diseases, called autoimmune diseases, occur when the body's immune system reacts against healthy cells, causing inflammation that affects mainly the locomotor system. Diagnosis is based on history and physical examination, since laboratory tests have low sensitivity and specificity. Therefore, the identification is difficult and many times it can be confused with other pathologies. Moreover, patients with autoimmune diseases can develop secondary diseases, such as ocular complications like uveitis, dry keratoconjunctivitis, episcleritis, scleritis, and others. Thus, the manifestations vary according to the type of rheumatism expressed, as well as the treatment to be applied. Final consideration: Rheumatic disorders
\end{abstract}

\footnotetext{
1 Universidade de Fortaleza (UNIFOR), Fortaleza - CE. *E-mail: luizvasconceloscosta@gmail.com

2 Universidade Municipal de São Caetano do Sul São Paulo (USCS SP), São Paulo - SP.

3 Universidad de San Martín de Porres (USMP), Lima - PER.

${ }^{4}$ Faculdade Atenas (ATENAS), Sete Lagoas - MG.

6 Universidade Nove de Julho (UNINOVE), Bauru - SP.
} 
cause ocular manifestations that should be followed by professionals in the area, in order to prevent and/or diagnose them.

Key words: Rheumatic diseases, Eye manifestations, Eye diseases.

\section{RESUMEN}

Objetivo: Analizar sobre las diversas alteraciones oculares relacionadas con las enfermedades reumáticas, así como discutir su etiología, fisiopatología, manifestaciones clínicas, factores de riesgo, enfoque diagnóstico y terapéutico. Revisión de la literatura: Las enfermedades reumáticas, conocidas como enfermedades autoinmunes, se producen cuando el sistema inmunitario del organismo reacciona contra las células sanas, provocando una inflamación que afecta principalmente al aparato locomotor. El diagnóstico se basa en la historia y la exploración física, ya que las pruebas de laboratorio tienen una sensibilidad y especificidad bajas. Por ello, su identificación es difícil y muchas veces puede confundirse con otras patologías. Además, los pacientes con enfermedades autoinmunes pueden desarrollar enfermedades secundarias, como complicaciones oculares como uveítis, queratoconjuntivitis seca, epiescleritis, escleritis, entre otras. Así, las manifestaciones varían en función del tipo de reumatismo expresado, así como del tratamiento a aplicar. Consideración final: Los trastornos reumáticos provocan manifestaciones oculares que deben ser vigiladas por los profesionales del área para prevenirlas y/o diagnosticarlas.

Palabras clave: Enfermedades reumáticas, Manifestaciones oculares, Oftalmopatías.

\section{INTRODUÇÃO}

As doenças reumáticas são de amplo espectro assim como as manifestações por elas produzidas. Nesse sentido, o envolvimento ocular é amplo em suas complicações e provém de um quadro clínico evoluído de reumatismo que, necessita de diagnóstico prévio e tratamento adequado com imunossupressores. Assim, o quadro clínico é característico de uma inflamação não contida e limitação fisiológica do órgão acometido por tal disfunção autoimune (ROCHA FAC, et al., 2018).

O acometimento ocular gerando ceratoconjuntivite sicca (10-30\%), uveíte (8\%), esclerite (5\%) e episclerite (4\%) pode indicar uma doença reumática, visto que, algumas vezes, pode preceder as manifestações articulares. As patologias reumáticas que possuem envolvimento ocular mais predominantes são: artrite reumatoide, espondiloartrites HLA-B27 positivas (como a espondilite anquilosante), lúpus eritematoso sistêmico, granulomatose com poliangeíte e a doença de Behçet (KEMENY-BEKE A e SZODORAY P, 2019).

No olho, as células dendríticas são a primeira barreira imunológica; há um ambiente ocular inibitório por meio da regulação do estado pró-inflamatório sistêmico, que ocorre a partir do desvio imune associado à câmara interior (ACAID). As doenças reumáticas af etam o ACAID, gerando inflamação (GENERALI E, et al., 2015).

A abordagem e diagnóstico do paciente acometido por complicações oculares associadas ao reumatismo necessitam de um médico oftalmologista que realize o devido exame clínico, físico e complementar, como biópsias, fundoscopia e acuidade visual. Tais visto que a perda de visão é um dos sinais frequentes das retinopatias, assim como perda de acuidade visual, palidez e edema na retina. Portanto, o grau de avanço da manifestação ocular no diagnóstico clínico é imprescindível para que não ocorra alastramento sistêmico (PEREIRA IA, 2011).

Existem diversas complicações oculares como ceratoconjuntivite sicca, episclerite, esclerite, uveíte, entre outras. Dentre elas, a uveíte, uma inflamação de parte ou de toda a úvea (composta pelo conjunto da íris, membrana coróide e processos ciliares). A uveíte pode situar-se na região anterior ao cristalino, posterior a este e até intermediária ao nível do cristalino. Tal manifestação patológica pode possuir como causa doenças reumáticas principalmente ligadas a espondiloartrites, sendo a principal manifestação extra-articular dessa condição reumatológica (VALE IMS, et al., 2018).

A terapêutica utilizada no manejo desses pacientes é objeto de estudo científico. Dentre os fármacos utilizados, tem-se o infliximabe e o adalimumabe. Tais fármacos possuem diversos mecanismos de ação, 
formando complexos estáveis com o fator de necrose tumoral alfa (TNFa) humano, diminuindo sua atuação no processo estimulatório na inflamação (VALE IS, et al., 2018).

Um estudo feito observando o uso de infliximabe durante seis meses em cinco pessoas que possuíam uveíte posterior aguda e resistência a fármacos imunossupressores com grave risco de perda visual, demonstrou que quatro dos cinco pacientes evoluíram seu tratamento apresentando melhora marcante na turvação do vítreo e acuidade visual e, consequentemente, a remissão da uveíte, permitindo a retirada de um imunossupressor que anteriormente era estabelecido como res olutivo para a doença autoimune. Dessa forma, os autores compreenderam a ef etividade da resposta no tratamento de uveíte posterior refratária (PEREIRA IA, 2011).

O estudo teve como objetivo delinear e analisar os artigos que expressam uma ampla visão sobre as manifestações oculares e como se desenvolvem quando relacionadas às doenças reumatológicas, analisando desde sua etiologia, fisiopatologia, manifestações clínicas aderidas aos possíveis fatores de riscos, até a abordagem diagnóstica e terapêutica utilizada, considerando eventuais casos refratários aos medicamentos comumente utilizados.

\section{REVISÃO BIBLIOGRÁFICA}

A uveíte pode acometer a porção posterior, anterior e intermediária sendo tal complicação a manifestação mais frequente na espondilite anquilosante. Contudo, o mecanismo patogênico pelo qual a Uveíte Anterior Aguda (UAA) atua ainda não é claramente elucidado, porém acredita-se que seja através de uma reação imunológica imediata com atuação de diferentes recursos tais como os Toll-Like Receptores (TLRs), vitamina D e TNF alfa. Além disso, algumas literaturas associam a UAA com a presença do gene HLA-B27, já que por meio dessa molécula células TCD8 são ativadas para controlar uma infecção (MITULESCU TC, et al.,2018).

Uma série de manifestações corneanas também podem ocorrer na artrite reumatóide. Essa enfermidade caracteriza-se por ser uma doença inflamatória crônica, a qual a etiologia permanece desconhecida, sendo marcada pela presença de edema articular, sensibilidade e destruição do tecido, dessa forma incapacitando a locomoção do indivíduo. O envolvimento da córnea pode af etar a acuidade visual, principalmente quando já encontra-se uma infecção subjacente. A episclerite e a esclerite também são patologias comuns, sendo comumente provocadas por uma doença do tecido conjuntivo (KEMENY-BEKE A e SZODORAY P, 2019).

Outra patologia que resulta em desconforto ocular é a ceratoconjuntivite sicca. Essa doença tem o potencial de evoluir com a baixa de acuidade visual, xeroftalmia, sensação de corpo estranho, fotofobia e dor ocular. A causa mais habitual é o dano inflamatório lacrimal, descrito em doenças autoimunes, como a síndrome de Sjögren. A fisiopatologia caracteriza-se por uma inflamação que gera destruição do tecido e bloqueio neurossecretor potencialmente reversível. Os anticorpos circulantes para o receptor M3 também podem causar um bloqueio na secreção lacrimal (PETRIS CK e ALMONY A, 2012).

Além disso, são descritas, entre as patologias reumáticas com acometimento oftalmológico, as espondiloartrites (EspA), as quais compreendem um conjunto de doenças (espondilite anquilosante, artrite psoriásica, artrite reativa, artrite enteropática e a espondiloartrite indiferenciada). Apesar da elevada incidência de uveítes entre pacientes com EspA seja conhecida, o entendimento dos fatores preditores e mecanismos da evolução das mesmas ainda é limitado. As inflamações oculares costumam ser anteriores, agudas, recorrentes, unilaterais, alternantes e com baixo grau de complicação. Em sua fisiopatologia, tem-se um aumento de diferentes citocinas pró-inflamatórias, especialmente o TNF alfa (VALE IMS, et al., 2018).

Dias CZ, et al. (2017), determina que há uma enorme gama de doenças reumáticas. Essas englobam um conjunto de doenças muito antigas, sendo elas tidas como incapacitantes dentro da prática clínica, incluindo mais de 100 condições diferentes. Entre essas patologias, algumas das principais incluem: artrite reumatóide (AR), espondilite anquilosante e Lúpus Eritematoso Sistêmico (LES) (SANGHA O, et al., 2000).

Quando se consideram essas afecções, cada uma com manifestações clínicas diferentes, as quais acometem sistemicamente o corpo humano, vai de encontro à dificuldade de tentar agrupar características comuns de cada uma, por exemplo, unindo os acometimentos oculares de cada uma dessas doenças. Ao 
considerar o grupo principal de manifestações oculares dessas doenças, tem-se que, para a AR, os principais achados são: esclerite, episclerite, ceratite esclerosante e estromal aguda, ceratoconjuntivite sicca secundária, úlcera periférica e "melting" da córnea (BETTERO RP, et al., 2008).

Sonoda RT, et al. (2021), afirma que ainda na tentativa de agrupar todas as manifestações oculares, com relação à espondilite anquilosante, alguns dos achados são a uveíte, irite, iridociclite, ptose e miopização. Mendes LE, et al. (1998), certifica que ao analisar o LES, encontra-se as principais manifestações oculares o olho seco, desepitelização corneana do terço inferior, catarata subcapsular posterior e alterações do epitélio pigmentado da retina na mácula. Percebe-se, dessa forma, a dificuldade de unir todas as manifestações of talmológicas em um grupo homogêneo de acometimentos. Dessa forma, nota-se a relevância de analisar cuidadosamente tais alterações oculares causadas por doenças autoimunes (SONODA RT, et al., 2021).

Ao analisar os principais fatores de risco para o desenvolvimento dessas principais doenças reumatológicas, observa-se uma grande heterogeneidade de achados epidemiológicos, a exemplo da AR, que apresenta mais de $50 \%$ de contribuição genética para o desenvolvimento da doença. Ademais, outro achado prevalente é o sexo feminino, sendo também um fator de risco. Outrossim, há uma relação conhecida entre o tabagismo e o desenvolvimento da AR (GOELDNER I, et al., 2011).

Gouveia EB, et al. (2012), demonstra ainda sob esse aspecto que a espondilite anquilosante acomete majoritariamente homens brancos e com HLA-B27 positivo. Além disso, tem-se como alguns fatores de risco para o desenvolvimento do LES a predisposição genética, sexo feminino, estresse, tabagismo, entre outros (PEZZOLE ER e OSELAME GB, 2014).

O diagnóstico das doenças reumáticas é essencialmente feito pela história clínica associado ao minucioso exame físico. Observa-se que exames laboratoriais e análises de imagens são caros e, normalmente, de pouca utilidade, devido à baixa sensibilidade e especificidade. Portanto, os resultados raramente são definitivos para a identificação, dificultando o diagnóstico da doença. Por exemplo, os níveis séricos de ácido úrico, uma substância envolvida na patogênese da gota, são de pouca utilidade diagnóstica em casos de artrite gotosa, visto que se encontram normais em $20 \%$ dos pacientes com gota. Além disso, a maioria dos indivíduos que apresentam níveis elevados não desenvolverá a doença. Dessa forma, investigações abrangentes e caras, muitas vezes, levam a conclusões equivocadas. Nesse sentido, a insuficiência de ferramentas laboratoriais auxiliares úteis para o diagnóstico da doença reumática torna as habilidades clínicas do médico indispensáveis (GOELDNER I, et al., 2011).

No que tange às manif estações clínicas das doenças reumatológicas, é possível que o of talmologista inicie a suspeita diagnóstica a partir do exame de fundo de olho, com análise do nervo óptico, bem como das artérias e veias que irrigam. Entre algumas da manifestações oculares mais comuns, destaca-se a conjuntivite, esclerite e uveíte da AR; a síndrome do olho seco no LES e na síndrome de Sjögren, com relato de ardência e hiperemia ocular, além de fotofobia; hiperemia conjuntival com evolução para uveíte ou catarata na espondilite anquilosante; e, por fim, alterações visuais, como turvação, diplopia ou cegueira em um ou ambos os olhos (TREVISANI VFM, 2014).

Aproximadamente $50 \%$ dos pacientes com oclusão arterial ocular na doença reumática demonstram ecocardiograma alterado, que pode estar associado à endocardite bacteriana, doença valvular cardíaca, infarto do miocárdio, prótese valvar, cardiopatia congênita e fibrilação atrial. Além disso, foram relatados casos de deficiência de proteínas anticoagulantes endógenas à exemplo de antitrombina III, proteína $C$, proteína $S$ e mutação do fator $V$ de Leiden, que podem se apresentar em pacientes com oclusão de vasos retinianos nas doenças reumáticas (PEREIRA IA, 2011).

O diagnóstico diferencial da artrite reumatóide inclui outras poliartrites, a osteoartrite, a fibromialgia e algumas doenças sistêmicas autoimunes que podem se apresentar com dores articulares. A fibromialgia, por exemplo, é uma patologia que acomete principalmente mulheres jovens e se caracteriza por dores em várias regiões do corpo, além dos pontos extra-articulares. As pacientes se queixam, também, de distúrbios do sono e podem relatar outros sinais e sintomas associados à dor, como síndrome do intestino irritável e enxaquecas frequentes. Embora as queixas da fibromialgia e da AR sejam, em princípio, diferentes, em alguns casos 0 
diagnóstico diferencial se torna difícil, pois alguns pacientes com AR apresentam dores musculares disseminadas, enquanto outros podem desenvolver ambas as situações clínicas concomitantemente, a AR e a fibromialgia (SOCIEDADE BRASILEIRA DE REUMATOLOGIA, 2011).

Devido a isso, a análise de manifestações oculares apresenta-se como uma forma eficiente de fazer de elencar o diagnóstico diferencial de doenças reumatológicas. É através do entendimento elucidado pelo médico das variadas apresentações de inflamações do globo ocular e dos possíveis diagnósticos diferenciais para cada patologia que consegue-se reduzir o tempo necessário para a conclusão do raciocínio diagnóstico, direcionar a terapêutica, o prognóstico oftalmológico, bem como a perspectiva de vida dos pacientes. Esse domínio é essencial, já que certas manifestações oculares podem representar gravidade da doença, funcionando como um indicador da inflamação e do comprometimento sistêmico (TEIXEIRA MEF, 2021).

Pacientes com LES podem apresentar artralgias intensas, porém inflamação persistente e deformidades articulares são raras nesta doença, o que a difere da AR. Uma das fontes de confusão no diagnóstico diferencial destas duas doenças é a presença do fator antinuclear positivo (FAN). Outras doenças podem ser confundidas, bem como as espondiloartropatias soronegativas, sendo elas a espondilite anquilosante, a síndrome de Reiter (artrite reativa), a artrite psoriásica e as artrites associadas a problemas intestinais (enteropática). O envolvimento das articulações sacroilíacas e da coluna lombar, as manifestações extraarticulares características (dermatite, uretrite, diarréia, entre outras) e a persistência do fator reumatóide negativo são diferenciais com a AR utilizados no raciocínio diagnóstico (VIANA D, et al.,2021)

Algumas doenças sistêmicas podem apresentar em seu quadro clínico dores articulares. Exemplificando, há o eritema nodoso, a endocardite bacteriana, o hipotireoidismo, a anemia falciforme, a febre reumática, a febre familiar do mediterrâneo, entre outras. Porém, difere da AR por caracterizarem em sua maioria com dores articulares de curta duração, as quais não evoluem para deformidades, além de geralmente terem associação com uma ampla gama de sinais e sintomas que não são comuns na AR. O Quadro 1 mostra os principais diagnósticos diferenciais da artrite reumatóide (SOCIEDADE BRASILEIRA DE REUMATOLOGIA, 2011).

Quadro 1 - Principais diagnósticos diferenciais nas manifestações de doenças reumáticas.

\begin{tabular}{|l|l|}
\hline Achados clínicos em doenças reumáticas & Diagnósticos diferenciais \\
\hline $\begin{array}{l}\text { Náuseas e vômitos que não melhoram com } \\
\text { medicação }\end{array}$ & $\begin{array}{l}\text { Lesão de massa no sistema nervoso central (SNC); } \\
\text { meningite }\end{array}$ \\
\hline Rigidez de nuca e febre & Meningite \\
\hline $\begin{array}{l}\text { Alterações neurológicas focais, cefaleia com } \\
\text { alteração comportamental, alteração do nível de } \\
\text { consciência e epilepsia }\end{array}$ & Neoplasia ou infecção neurológica \\
\hline Meningismo & Hemorragia subaracnóidea (HSA) \\
\hline Sinais de síndrome de Horner & Dissecção de artéria \\
\hline Papiledema & $\begin{array}{l}\text { Meningoencefalite; lesão de SNC; pseudotumor } \\
\text { cerebral }\end{array}$ \\
\hline Dor no globo ocular & $\begin{array}{l}\text { Glaucoma agudo de ângulo fechado; infecção ou } \\
\text { tumor orbitário }\end{array}$ \\
\hline $\begin{array}{l}\text { Claudicação mandibular ou mialgias, espessamento } \\
\text { focal da artéria temporal }\end{array}$ & Arterite temporal \\
\hline Piora da dor com manobra de Valsalva & Síndrome de Arnold-Chiari \\
\hline
\end{tabular}

Fonte: VASCONCELOS LVC, et al., 2021. 
Foulks GN, et al. (2015) aponta que a abordagem terapêutica nas manifestações oculares das doenças reumatológicas depende da causa e das manifestações que cada paciente apresenta, ou seja, a abordagem vai desde o uso de lubrificantes para os olhos, o uso de Anti-Inflamatórios Não Esteroidais (AINEs) e corticosteróides, entre outros. As principais doenças reumatológicas com acometimento ocular são as seguintes: as espondiloartrites, a artrite reumatóide e a síndrome de Sjögren (GENERALI E, et al., 2015).

As espondiloartrites são doenças crônicas que afetam principalmente as articulações. Apesar de ter um ef eito predominantemente articular, também ocorrem manifestações extra-articulares; entre elas, afecções oftalmológicas, como a uveíte. O tratamento da uveíte vai desde o uso de AINEs, corticosteroides e, mais recentemente, o tratamento biológico com bloqueadores de TNF alfa que são usados na uveíte refratária (GUPTA N, 2018).

Entre os estudos analisados, houve uma coorte com uma amostra de 914 pacientes em cinco clínicas nos Estados Unidos, o qual avaliou os benefícios e complicações no uso de injeções de corticosteróides de depósito periocular para o tratamento da uveíte. Neste trabalho, verificou-se que essas injeções foram eficazes na melhoria da inflamação intraocular ativa e na redução da acuidade visual causada pelo edema macular causado pela inflamação uveal (NIDA H, et al., 2014).

Na síndrome de Sjögren, a manif estação ocular mais frequente é o olho seco. Em outro estudo de revisão sistemática, foi apresentado um algoritmo de tratamento em etapas que dependiam da natureza do olho seco e da gravidade dos sintomas, o qual poderá auxiliar na conduta terapêutica de cada paciente. Aponta que na primeira manifestação da doença, a abordagem inicial é através de lágrimas artificiais (lubrificantes oculares), o uso de suplementos nutricionais, como o ômega 3; além de anti-inflamatórios, corticoides tópicos, ciclosporina e os secretagogos orais (FOULKS GN, et al., 2015).

Episclerite, esclerite e ceratite são as manifestações oculares comumente apresentadas na AR e na granulomatose com poliangeíte. Dos quais, a episclerite tende a se resolver espontaneamente, todavia o uso de corticosteróides ajuda na melhora rápida dos sintomas. A abordagem terapêutica destes consiste essencialmente no uso de corticoides tópicos e, no caso da esclerite, a terapia combinada com ciclosporina é útil (GENERALI E, et al., 2015).

\section{CONSIDERAÇÕES FINAIS}

As doenças reumáticas autoimunes, caracterizadas por af etarem o aparelho locomotor, englobam um conjunto de af ecções que acometem grande parte da população mundial. O quadro clínico dessas patologias é evidenciado por meio de uma inflamação que pode levar ao comprometimento fisiológico do órgão af etado. Nesse sentido, os pacientes acometidos podem apresentar manifestações secundárias, principalmente oculares. Dessa maneira, torna-se necessário o diagnóstico precoce, assim, reduzindo a probabilidade do desenvolvimento desses distúrbios. Em relação ao acometimento ocular, é imprescindível o acompanhamento por um médico oftalmologista a fim de diagnosticar quaisquer possíveis complicações oftalmológicas, tais como: uveíte, ceratoconjuntivite sicca, episclerite, esclerite, entre outras. As manifestações oculares variam de acordo com o tipo de doença reumática, assim como o tratamento a ser aplicado.

\section{REFERÊNCIAS}

1. BETTERO RP, et. al. Prevalência de manifestações oculares em 198 pacientes com artrite reum atóide: um estudo retrospectivo. Arquivos Brasileiros de Oftalmologia. 2008; 71:365-369.

2. DIAS CZ, et al. Perfil dos usuários com doenças reumáticas e fatores associados à qualidade de vida no sistema único de saúde, Brasil. Rev Méd Minas Gerais. 2017;27: 1-7.

3. FOULKS GN, et al. Clinical Guidelines for management of dry eye associated with Sjögren disease. The Ocular Surface, 2015;13: 118-132.

4. GENERALI E, et. al. Ocular Involvement in Systemic Autoimmune Diseases. Clinical Reviews In Allergy \& Immunology. Springer Science and Business Media LLC. 2015;49: 263-270.

5. GOELDNER I, et al. Artrite reumatóide: uma visão atual. Journal Brasileiro de Patologia Médica Laboratorial. 2011; 47: 495-503. 
6. GOUVEIA EB, et al. Espondilite anquilosante e uveíte: revisão. Revista Brasileira de Reumatologia. 2012; 52: 749756.

7. GUPTA N. Management of Uveitis in Spondyloarthropathy: Current Trends. The Permanente Journal. $2018 ; 22$ : 17 41.

8. KEMENY-BEKE A, SZODORAY P. Ocular manifestations of rheumatic diseases. International Ophthalmology Springer Science and Business Media LLC. 2019;40(2): 503-510.

9. KURODA K, et.al. Late-Onset Systemic Lupus Erythematosus Associated with Autoinmune Hemolytic Anemia and Sixth Cranial Nerve Palsy. American Journal of Case Reports. 2021;22: 1-5.

10. MENDES LE, et. al. Alterações oculares no lupus eritematoso sistêmico. Arquivos Brasileiros de Oftalmologia. GN1 Genesis Network. 1998;61:713-716.

11. MITULESCU TC, et. al. Advances in the treatment of uveitis in patients with spondyloarthritis - is it the time for biologic therapy? Romanian Journal Of Ophthalmology. Fundatia Universitara Sanabuna. 2018;61:114-122.

12. NIDA HS, et al. Periocular corticosteroid injections in uveitis: effects and complications. Ophthalmology, 2014; 121 : 2275-2286.

13. PEREIRA IA. Envolvimento ocular nas doenças reumáticas. Revista Brasileira de Reumatologia. 2011; 44:160-167.

14. PETRIS CK, ALMONY A. Manifestações oftálmicas da doença reumatológica: diagnóstico e gestão. Missour Medicine. 2012;109: 53-58.

15. PEZZOLE ER, OSELAME GB. Fatores de risco para o lúpus eritematoso sistêmico: revisão da literatura. Revista Uniandrade. 2014;15:65-77.

16. ROCHA FAC, et. al. Advances in rheumatology practice in Brazil. Rheumatology International. Springer Science and Business Media LLC. 2018;39:1125-1134.

17. SANGHA O. Epidemiology of rheumatic diseases. Rheumatology Oxford. 2000;39: 3-12.

18. SOCIEDADE BRASILEIRA DE PEDIATRIA. 2014. In: O que é Febre Reumática?. Disponível em: https://www.sbp.com.br/imprensa/detalhe/nid/o-que-e-febre-reumatical. Acessado em:15 de nov. de 2021.

19. SOCIEDADE BRASILEIRA DE REUMATOLOGIA. 2011. In: Síndrome da Fibromialgia-Diagnóstico Diferencial. Disponível em: https://www.reumatologia.org.br/orientacoes-ao-paciente/sindrome-da-fibromialgia-diagnosticodiferencial/. Acessado em:15 de nov. de 2021.

20. SONODA RT, et al. Espondilite Anquilosante, distúrbios sistêmicos e oculares. Revista Científica Multidisciplinar. 2021; 2: 717-971.

21. SPINA GS. Doença reumática:negligenciada, mas ainda presente e mortal. Revista de Medicina. Universidade de São Paulo, Agência USP de Gestão da Informação Academica (AGUIA). 2008; 87: 128.

22. TEIXEIRA MEF. Avaliação da concordância de diagnóstico das doenças reumáticas entre os níveis primário e terciário de atenção à saúde. 2021, 1:1-33.

23. TREVISANI VFM. Manifestações oftalmológicas em reumatologia. Revista Paulista de Reumatologia, São Paulo. 2014;1: 11-13.

24. VALE IMS. Análise da frequência de uveítes em pacientes com espondiloartrites, suas complicações e associação com parâmetros clínicos da doença. Revista Brasileira de Oftalmologia. 2018;77:80-4.

25. VIANA D, et al. Polimialgia Reumática, Quando suspeitar?. $2021 ; 11: 49-5$. 